\section{Contribuições do modelo Fatores Críticos de Sucesso para análise da gestão de Parcerias para o Desenvolvimento Produtivo de um laboratório oficial}

\author{
Contributions from the Critical Success Factors \\ model to analysis of the management of \\ Product Development Partnerships in a \\ government laboratory
}

\section{Contribuciones del modelo de Factores Críticos de Éxito para el análisis de la gestión de Alianzas para el Desarrollo Productivo de un laboratorio oficial}




\section{Introdução}

O setor farmacêutico, por sua alta complexidade e relevância para a saúde, demanda uma geração constante de inovações. No Brasil, porém, constata-se uma forte dependência tecnológica externa na área de produtos para a saúde. O resultado da balança comercial, com déficits acumulados em relação a esses produtos, evidencia o fraco desempenho do setor produtivo nacional. No final de 2015, o déficit na balança comercial da saúde era de aproximadamente 10 bilhões de dólares, sendo que os fármacos e os medicamentos, em conjunto, representavam $50 \%$ desse déficit 1.

Diante disso, o país, para fortalecer a capacidade tecnológica das indústrias farmacêuticas brasileiras e ampliar a sua taxa de inovação, tem, não somente fomentado diretamente as atividades de pesquisa e desenvolvimento (P\&D), como também usado o seu alto poder de compra, para influenciar produtores estrangeiros a transferirem tecnologias relevantes ao país, utilizando como instrumentos as Parcerias de Desenvolvimento Produtivo (PDPs).

Essas parcerias têm como característica a cooperação entre instituições públicas e privadas, nacionais ou de capital estrangeiro, para o desenvolvimento, transferência e absorção de tecnologia. Mediante um acordo, o ente privado se compromete a transferir a tecnologia ao ente público, para que este possa, em um prazo de até dez anos, conforme a complexidade da transferência, fabricar e fornecer medicamentos e equipamentos médicos prioritários para o Sistema Único de Saúde (SUS). Como incentivo ao laboratório privado, o governo garante a exclusividade na compra desses produtos durante o mesmo período.

As PDPs são subdividas em quatro fases, classificadas segundo o estágio de desenvolvimento:

(i) Fase I - Proposta de projeto de PDP: submissão da proposta e análise pelas Instâncias de Avaliação, Comissão Técnica de Avaliação (CTA) e Comitê Deliberativo (CD), que são coordenadas pela Secretaria de Ciência, Tecnologia e Insumos Estratégicos do Ministério da Saúde (SCTIE/MS), celebração do termo de compromisso entre o Ministério da Saúde e a instituição pública, e publicação no Diário Oficial da União;

(ii) Fase II - Projeto de PDP: quando ocorre a assinatura do contrato entre a instituição pública e a empresa privada, publicação do registro sanitário na Agência Nacional de Vigilância Sanitária (Anvisa) pelo parceiro privado e desenvolvimento do produto pelo parceiro privado;

(iii) Fase III - PDP: primeiro fornecimento do medicamento ao Ministério da Saúde, publicação do registro sanitário pelo instituto público, alteração do local de fabricação, transferência e absorção da tecnologia do medicamento e início da produção, conforme o cronograma dos acordos;

(iv) Fase IV - Internalização de tecnologia: com a conclusão do desenvolvimento, transferência e absorção da tecnologia objeto da PDP em condições de produção do produto no país, fim do fornecimento do medicamento por exclusividade e portabilidade tecnológica por parte do instituto público e parceiro privado 2 .

Os laboratórios farmacêuticos públicos (LFOs), importantes atores nesse processo, têm papel relevante tanto na regulação do mercado como no fornecimento rotineiro e emergencial dos medicamentos essenciais à população. Contudo, têm como característica a dependência de produtos de outras instalações industriais de química fina, localizadas no país ou no exterior, pois não são, historicamente, produtores de matérias-primas ${ }^{3}$.

Essas parcerias fazem parte da Política de Desenvolvimento Produtivo que iniciou em 2008, como uma estratégia do Governo Federal de apoio ao desenvolvimento do Complexo Industrial da Saúde (CIS) 4. Uma das primeiras medidas nesse sentido foi a criação do Grupo Executivo do Complexo Industrial da Saúde (GECIS), com a diretriz de promover medidas e ações concretas visando à criação e implantação do marco regulatório brasileiro, bem como propor outras medidas complementares 5 .

Em 2009, foram aprovados os primeiros acordos para a transferência de tecnologia entre laboratórios públicos e empresas privadas (11 ao todo) 6. Alguns anos depois, foi publicada a Portaria GM/MS no 837/2012 7, trazendo uma nova denominação para essas parcerias, que passaram a ser chamadas de Parceria para o Desenvolvimento Produtivo, e definindo as diretrizes e os critérios para o seu estabelecimento.

Até 2014, apesar de já existirem várias PDPs em andamento, muitas dúvidas ainda persistiam a respeito do seu funcionamento. A forma de contratação e as próprias diretrizes e regras para a formalização de uma parceria não estavam totalmente claras. Diante desse cenário, foi publicada a 
Portaria GM/MS no 2.531/2014 8 em novembro de 2014, que redefiniu as diretrizes e os critérios para a definição da lista de produtos estratégicos para o SUS, em conformidade com as recomendações expedidas pelo GECIS, e ainda trouxe novas regras para o estabelecimento, avaliação e gestão das PDPs, conferindo, assim, uma maior segurança jurídica ao programa.

O monitoramento das PDPs é realizado pelo Comitê Técnico Regulatório (CTR), composto por representantes da Anvisa, Ministério da Saúde e dos laboratórios públicos envolvidos. Esse acompanhamento é feito por meio de reuniões e visitas técnicas realizadas pelo Departamento do Complexo Industrial e Inovação em Saúde (DECIIS) aos laboratórios públicos e privados, e pela análise dos relatórios de acompanhamento pela SCTIE/MS, a cada quatro meses.

Apesar das contribuições que as PDPs trazem aos laboratórios públicos e ao SUS, algumas dificuldades ainda persistem, tais como a carência de expertise na transferência de tecnologia do setor privado para o público, a limitação dos produtores públicos em relação à competência técnica, a insuficiente capacidade de gestão dos laboratórios e a dificuldade de ajuste às boas práticas de fabricação preconizadas pela Anvisa 9.

Tais dificuldades se expressam no balanço das PDPs. Desde o início da política, em 2009, até maio de 2018, das 148 parcerias aprovadas para todo o Brasil, com o envolvimento de 19 laboratórios públicos e 50 laboratórios privados 10, 27 foram extintas e somente 4 haviam concluído a internalização da tecnologia 6 . Esse resultado revela uma baixa efetividade dessas parcerias e a existência de lacunas e/ ou fatores que merecem uma análise mais aprofundada, com o objetivo de aumentar a taxa de sucesso em relação à transferência de tecnologia aos produtores públicos nacionais.

Mapear e monitorar continuamente fatores críticos desses projetos (atividades ou áreas), a fim de subsidiar o planejamento estratégico e a tomada de decisões para cada etapa, é uma importante iniciativa para o alcance desse objetivo.

A identificação dos Fatores Críticos de Sucesso (FCS) permite que a organização promova ajustes nos projetos, identifique gargalos e focalize estrategicamente as suas ações, auxiliando desta forma a condução dos projetos que já estão em andamento e o planejamento dos que ainda serão implantados.

Neste trabalho, alinhando-se a uma abordagem contingencial, foram identificados os fatores críticos (FC) de um tipo específico de projeto e de parceria público-privada (PPP), que são as PDPs de medicamentos, usando como estudo de caso um laboratório farmacêutico público.

O termo parceria público-privada pode ser usado de forma estrita (contrato de concessão, conforme descrito na Lei no 11.079/2004) ou de forma ampla, indicando os "múltiplos vínculos negociais de trato continuado estabelecidos entre a Administração Pública e instituições privadas para viabilizar o desenvolvimento, sob a responsabilidade destes, de atividades com algum interesse geral" 11 (p. 22).

As PDPs, diferentemente das PPPs, se caracterizam como "uma modalidade de encomenda tecnológica realizada pelo Estado na presença de risco tecnológico” 12 (p. 2). Apesar das diferenças entre os dois tipos de parcerias, utilizou-se FCSs aplicados às PPPs do Governo Federal e ao gerenciamento de projetos para selecionar fatores a serem aplicados na avaliação da gestão das PDPs em um LFO.

O trabalho teve como objetivo analisar os fatores críticos que influenciam o sucesso das PDPs, a fim de contribuir para o aprimoramento da gestão desses projetos e para o aumento da taxa de sucesso dos mesmos.

\section{Métodos}

Foi realizado um estudo de caso em um LFO do Brasil, sobre a gestão de suas PDPs, no período de 2009 até maio de 2018.

Da revisão bibliográfica foram selecionados os critérios e FCSs em projetos e PPPs, com maior relação com as PDPs. Os mesmos constam das Tabelas 1 e 2 e balizaram a elaboração do instrumento semiestruturado aplicado nas entrevistas.

Para a identificação dos critérios foram consideradas as dimensões de sucesso de projetos sugeridas por Shenhar \& Dvir 13. Os fatores críticos das PPPs foram selecionados do estudo de Menezes 14 e de projetos, dos estudos de diversos autores sobre o tema, compilados por Morioka \& Carvalho 15.

Realizou-se um levantamento de documentos internos relativos ao monitoramento das parcerias do laboratório com o intuito de caracterizar suas respectivas trajetórias, e foram acessados 
Tabela 1

Critérios de sucesso para as Parcerias para o Desenvolvimento Produtivo (PDPs).

\begin{tabular}{|c|c|c|c|c|}
\hline Critério de sucesso & Atores internos (média) & Laboratório privado & Ministério da Saúde & Somatório das notas \\
\hline Impacto para o cliente & 5 & 5 & 5 & 15 \\
\hline Preparação para o futuro & 4 & 4 & 4 & 12 \\
\hline Negócio e impacto imediato & 2 & 2 & 3 & 7 \\
\hline Eficiência & 3 & 1 & 2 & 6 \\
\hline Impacto para a equipe & 1 & 3 & 1 & 5 \\
\hline
\end{tabular}

Fonte: baseado nas dimensões de sucesso definidas por Shenhar \& Dvir 13 .

Tabela 2

Fatores Críticos de Sucesso em parcerias público-privadas e em projetos de Parcerias para o Desenvolvimento Produtivo (PDPs).

\begin{tabular}{|c|c|c|c|c|c|}
\hline Tipo de fator & Fatores Críticos de Sucesso & $\begin{array}{l}\text { Atores internos } \\
\text { (nota média) }\end{array}$ & $\begin{array}{c}\text { Laboratório } \\
\text { privado }\end{array}$ & $\begin{array}{l}\text { Ministério da } \\
\text { Saúde }\end{array}$ & Total \\
\hline \multirow{10}{*}{$\begin{array}{l}\text { Parcerias público- } \\
\text { privadas (PPPs) }\end{array}$} & Interesse político & 7 & 7 & 7 & 21 \\
\hline & Marco regulatório adequado & 6 & 7 & 7 & 20 \\
\hline & Qualidade do projeto & 6 & 6 & 6 & 18 \\
\hline & Ambiente econômico favorável & 6 & 5 & 6 & 17 \\
\hline & Aparato institucional & 6 & 4 & 6 & 16 \\
\hline & Edital e contrato bem elaborado & 6 & 5 & 5 & 16 \\
\hline & $\begin{array}{l}\text { Prévia análise de custos e benefícios do } \\
\text { projeto }\end{array}$ & 5 & 5 & 5 & 15 \\
\hline & Risco político & 6 & 4 & 5 & 15 \\
\hline & $\begin{array}{l}\text { Compatibilidade entre as expectativas } \\
\text { dos parceiros }\end{array}$ & 5 & 3 & 6 & 14 \\
\hline & $\begin{array}{l}\text { Existência de uma cultura } \\
\text { empreendedora em PPP }\end{array}$ & 5 & 1 & 5 & 11 \\
\hline \multirow[t]{10}{*}{ Projetos } & Suporte da alta diretoria & 7 & 6 & 7 & 20 \\
\hline & Controle e monitoramento efetivos & 6 & 7 & 6 & 19 \\
\hline & Equipe suficiente e qualificada & 6 & 7 & 6 & 19 \\
\hline & Gestão de riscos efetiva & 6 & 6 & 7 & 19 \\
\hline & Orçamento adequado & 7 & 5 & 7 & 19 \\
\hline & Boa comunicação e bom feedback & 6 & 7 & 5 & 18 \\
\hline & Boa liderança & 6 & 6 & 5 & 17 \\
\hline & $\begin{array}{l}\text { Bom desempenho dos fornecedores e } \\
\text { contratados }\end{array}$ & 6 & 4 & 6 & 16 \\
\hline & Valor percebido do projeto & 6 & 5 & 5 & 16 \\
\hline & Treinamentos adequados & 6 & 5 & 5 & 16 \\
\hline
\end{tabular}

Fonte: baseado em Menezes 14.

documentos disponíveis para o público nos sites do Ministério da Saúde. Foram verificados os registros dos medicamentos na Anvisa, a transferência e absorção das tecnologias e o fornecimento e produção dos medicamentos.

De forma mais detalhada, procurou-se verificar a evolução das PDPs em andamento (Tabela 3) e o cumprimento de atividades previstas nos cronogramas dos acordos para algumas PDPs selecionadas da Fase III (Tabela 4). 
Tabela 3

Fatores internos e externos que tiveram influência para a evolução das Parcerias para o Desenvolvimento Produtivo (PDPs) do laboratório estudado.

\begin{tabular}{lcc}
\hline Fatores internos & $\mathbf{n}$ & Fator de importância relativa (\%) \\
\hline Planejamento insuficiente & 14 & 29 \\
Morosidade nas aquisições e obras devido à burocracia da máquina pública & 11 & 23 \\
Limitado acompanhamento das etapas e monitoramentos dos prazos & 7 & 15 \\
Baixa capacitação dos profissionais envolvidos & 7 & 15 \\
Baixo comprometimento de alguns setores no cumprimento de prazos & 3 & 6 \\
Centralização de informações na diretoria & 2 & 4 \\
Ausência de equipes de projetos dedicadas & 2 & 4 \\
Necessidade de readequação dos projetos a partir do marco regulatório em 2014 & 2 & 4 \\
Total & 48 & 100 \\
\hline Fatores externos & $\mathbf{n}$ & Fator de importância relativa (\%) \\
\hline Questões políticas & 13 & 41 \\
Falta de orçamento & 6 & 19 \\
Dificuldade relacionamento com os parceiros privados & 6 & 19 \\
Ausência de marco legal no início do programa & 3 & 9 \\
Burocracia dos órgãos reguladores, atrasando liberações & 2 & 6 \\
Ausência de orientação do Ministério da Saúde com relação às plataformas tecnológicas & 2 & 6 \\
Total & 32 & 100 \\
\hline
\end{tabular}

Fonte: elaboração própria.

\section{Tabela 4}

Percentual de desenvolvimento das Parcerias para o Desenvolvimento Produtivo (PDPs) no laboratório estudado, de acordo com a conclusão das atividades previstas por ano (maio de 2018).

\begin{tabular}{|c|c|c|c|c|c|c|c|c|c|c|c|c|}
\hline \multirow[t]{3}{*}{ Produto } & \multicolumn{10}{|c|}{ Fase III } & \multirow{3}{*}{$\begin{array}{c}\text { Soma- } \\
\text { tório }\end{array}$} & \multirow{3}{*}{$\begin{array}{c}\text { Per- } \\
\text { centual } \\
\text { médio } \\
\text { de con- } \\
\text { clusão da } \\
\text { PDP }\end{array}$} \\
\hline & & An & 101 & & An & 02 & Anc & 103 & Ano 4 & Ano 5 & & \\
\hline & $\begin{array}{l}1 \text { o forne- } \\
\text { cimento } \\
\text { do medi- } \\
\text { camento } \\
\text { objeto da } \\
\text { PDP }\end{array}$ & $\begin{array}{c}\text { Registro } \\
\text { sanitário } \\
\text { do medi- } \\
\text { camento } \\
\text { pela } \\
\text { insti- } \\
\text { tuição } \\
\text { pública }\end{array}$ & $\begin{array}{c}\text { Trans- } \\
\text { ferência } \\
\text { da meto- } \\
\text { dologia } \\
\text { analítica } \\
\text { do } \\
\text { medica- } \\
\text { mento }\end{array}$ & $\begin{array}{c}\text { Trans- } \\
\text { ferência } \\
\text { da meto- } \\
\text { dologia } \\
\text { analítica } \\
\text { do IFA }\end{array}$ & $\begin{array}{l}\text { Elabo- } \\
\text { ração } \\
\text { de ficha } \\
\text { técnica } \\
\text { de pro- } \\
\text { dução }\end{array}$ & $\begin{array}{l}\text { Análise } \\
\text { dos } \\
\text { excipi- } \\
\text { entes e } \\
\text { IFA im- } \\
\text { portado }\end{array}$ & $\begin{array}{c}\text { Fabri- } \\
\text { cação } \\
\text { dos lotes } \\
\text { pilotos } \\
\text { com IFA } \\
\text { nacio- } \\
\text { nal e/ou } \\
\text { impor- } \\
\text { tado }\end{array}$ & $\begin{array}{c}\text { Solicita- } \\
\text { ção de } \\
\text { inclusão } \\
\text { de novo } \\
\text { local de } \\
\text { fabrico }\end{array}$ & $\begin{array}{l}\text { Produ- } \\
\text { ção de } \\
\text { lotes } \\
\text { comer- } \\
\text { ciais com } \\
\text { IFA } \\
\text { impor- } \\
\text { tado }\end{array}$ & $\begin{array}{l}\text { Fabri- } \\
\text { cação do } \\
\text { medica- } \\
\text { mento } \\
\text { em } \\
\text { Farman- } \\
\text { guinhos } \\
\text { com IFA } \\
\text { nacional }\end{array}$ & & \\
\hline 4 & 100,0 & 100,0 & 66,7 & 33,3 & 33,3 & 66,7 & 0,0 & 0,0 & N/A * & 0,0 & 400,0 & 44,0 \\
\hline 7 & 100,0 & 100,0 & 66,7 & 66,7 & 66,7 & 66,7 & 0,0 & 0,0 & 0,0 & 0,0 & 466,8 & 47,0 \\
\hline 8 & 100,0 & 100,0 & 100,0 & 66,7 & 33,3 & 33,3 & 0,0 & 0,0 & 0,0 & 0,0 & 433,3 & 43,0 \\
\hline $\begin{array}{l}\text { Percentual } \\
\text { médio da } \\
\text { atividade }\end{array}$ & 100,0 & 100,0 & 73,0 & 47,0 & 40,0 & 40,0 & 7,0 & 0,0 & 0,0 & 0,0 & & 45,0 \\
\hline
\end{tabular}

Farmanguinhos: Instituto de Tecnologia em Fármacos, Fundação Oswaldo Cruz; IFA: insumo farmacêutico ativo; N/A: não se aplica.

Fonte: elaboração própria, baseada em relatórios de acompanhamento das PDPs.

* A PDP já tem o IFA nacionalizado. 
Na Tabela 5, são apresentadas as 10 PDPs que estavam em andamento em maio de 2018, separadas por fase, produtos contemplados e respectivos anos de início de cada fase da PDP. Os nomes dos produtos foram substituídos por números, pois a apresentação poderia levar à identificação do laboratório estudado e comprometer a privacidade de alguns entrevistados.

A comparação foi feita até a data de corte do estudo e por conta disto, o percentual encontrado pode ter sofrido alguma alteração, visto que os acordos dessas parcerias ainda estavam vigentes.

Para a mensuração do desenvolvimento dessas PDPs (Tabela 4) foram estabelecidos quatro estágios de cumprimento das atividades, e para cada um deles atribuiu-se notas: atividade concluída dentro do prazo previsto, 100; atividade concluída fora do prazo, 66,7; atividade não concluída no prazo e em andamento, 33,3 e atividade ainda não iniciada, 0 .

Foram identificadas 20 atividades previstas para a Fase III nos relatórios de acompanhamento dessas PDPs. Dessas, 10 foram selecionadas em consonância com as gerências dos projetos, por expressarem etapas relevantes e servirem como indicadores do efetivo andamento das PDPs.

Foram ainda realizadas entrevistas semiestruturadas com atores internos do laboratório oficial (o diretor geral, coordenadores e gerentes das PDPs, além de gestores dos setores administrativos e técnicos), e externos (1 gestor de um laboratório parceiro privado e 1 representante do Ministério da Saúde). No total, foram realizadas 17 entrevistas - 15 internas e 2 externas.

O roteiro das entrevistas contemplou questões fechadas, que foram ponderadas e pontuadas pelos entrevistados e questões abertas, que permitiram a complementação de informações.

As respostas das questões fechadas foram comparadas/somadas e com base nos resultados foram geradas porcentagens ou médias. Esses resultados estatísticos são apresentados nas Tabelas 1, 2 e 3. Já para as questões abertas, foi feita a transcrição das respostas e posteriormente a análise de seu conteúdo para que pudessem ser selecionados os aspectos de maior relevância para o atingimento do objetivo e resposta ao problema da pesquisa.

As seguintes dimensões foram abordadas: caracterização dos entrevistados, critérios de sucesso, FCSs; fatores internos e externos que efetivamente impactaram no estabelecimento das PDPs do laboratório estudado, além de perguntas específicas para alguns atores internos e para os atores externos.

Destacou-se a diferença entre critérios de sucesso e fatores de sucesso, visto que estes conceitos, muitas vezes, se confundem. Segundo Borges \& Carvalho 16 (p. 233), "critérios de sucesso são medidas a partir das quais o sucesso ou fracasso de um projeto é julgado. Já fatores de sucesso são as entradas do sistema gerencial que levam direta ou indiretamente ao sucesso do projeto".

Tabela 5

Parcerias para o Desenvolvimento Produtivo (PDPs) em andamento, por fase, produto, quantidade, porcentagem, ano de início das Fases II, III e IV Maio de 2018

\begin{tabular}{|c|c|c|c|c|c|c|}
\hline Situação & Quantidade & $\%$ & Produto & $\begin{array}{c}\text { Ano de início } \\
\text { da Fase II }\end{array}$ & $\begin{array}{c}\text { Ano de início } \\
\text { da Fase III }\end{array}$ & $\begin{array}{c}\text { Ano de início } \\
\text { da Fase IV }\end{array}$ \\
\hline \multirow[t]{2}{*}{ Fase IV - internalização da tecnologia } & 2 & 20 & 1 & 2009 & 2012 & 2017 \\
\hline & & & 2 & 2012 & 2013 & 2018 \\
\hline \multirow[t]{6}{*}{ Fase III - PDP } & 6 & 60 & 3 & 2009 & 2015 & - \\
\hline & & & 4 & 2012 & 2014 & - \\
\hline & & & 5 & 2011 & 2015 & - \\
\hline & & & 6 & 2011 & 2015 & - \\
\hline & & & 7 & 2011 & 2014 & - \\
\hline & & & 8 & 2011 & 2014 & - \\
\hline \multirow[t]{2}{*}{ Fase II - projeto de PDP } & 2 & 20 & 9 & 2012 & - & - \\
\hline & & & 10 & 2009 & - & - \\
\hline Total & 10 & 100 & & & & \\
\hline
\end{tabular}

Fonte: elaboração própria. 
O projeto de pesquisa, cujos resultados serão a seguir apresentados, foi submetido e aprovado pelos Comitês de Ética em Pesquisa (CEP) da Escola Nacional de Saúde Pública Sergio Arouca (ENSP) e do Instituto Nacional de Infectologia (INI), Fundação Oswaldo Cruz (Fiocruz), conforme os pareceres consubstanciados de números 2.653 .570 e 2.765.581. Todos os respondentes assinaram o Termo de Consentimento Livre e Esclarecido (TCLE) no momento das entrevistas.

\section{Resultados e discussão}

A escolha dos entrevistados contribuiu para a valorização dos resultados alcançados, visto que $40 \%$ atuam principalmente na gestão estratégica das parcerias (tomada de decisão e planejamento), e 60\% fazem parte do gerenciamento e/ou execução dos projetos. Essa distribuição permitiu que diferentes conhecimentos e percepções fossem agregados, já que houve a participação de pessoas que atuam desde a concepção até a execução das PDPs.

Quanto aos critérios de sucesso (Tabela 1), verificou-se, corroborando com a função social das PDPs, que o impacto para o cliente foi considerado como o mais importante por todos os entrevistados. O impacto refere-se à melhoria da qualidade de vida da população e ao atendimento e satisfação das necessidades de saúde do SUS.

O segundo critério mais importante, também assim classificado por todos os entrevistados, foi a preparação para o futuro. Esse indicador contempla a visão de continuidade do LFO, que deve ser mantido em constante prospecção, visando a absorver conhecimentos que o capacitem para demandas futuras. As PDPs são tidas como um instrumento complementar para esse objetivo, visto que proporcionam aos LFOs recursos necessários à sua capacitação tecnológica e pessoal, além do conhecimento de novas tecnologias, fator indispensável para que se mantenham como instituições públicas de ponta.

Na Tabela 2, apresenta-se a ordem de importância atribuída pelos diferentes atores aos fatores críticos relativos a PPPs e gestão de projetos.

Em relação aos FCSs analisados para parcerias entre instituições públicas e privadas, observa-se que o interesse político, ou seja, o interesse na política pública, foi classificado como o mais importante, tanto pelos atores internos como pelos externos. Segundo os entrevistados, isso se deve ao fato de o programa ser totalmente dependente do poder de compra do governo e de sua vontade em continuar com a parceria até o final. Os entrevistados destacaram que sem o apoio político para a continuidade do programa e manutenção das obrigações assumidas, aumenta-se o risco e a insegurança na realização de novas parcerias.

Outro fator crítico relevante foi a necessidade de um marco regulatório adequado. A ausência de uma norma que defina as diretrizes e os critérios para as parcerias, gera insegurança e instabilidade aos acordos. Segundo os entrevistados, o marco regulatório atual (Portaria GM/MS no 2.531/2014) auxiliou na condução das parcerias, porém ainda apresenta alguns pontos que não estão bem claros e que poderiam ser melhor especificados e/ou aprimorados.

Quanto aos fatores críticos relacionados a projetos, o suporte da alta diretoria foi considerado como o mais importante. Tendo em vista que as PDPs são projetos de alta complexidade, exigem da cúpula organizacional uma visão geral dos projetos, para que apoiem a sua continuidade, captem recursos para os investimentos e tenham capacidade de tomar decisões frente às mudanças no contexto.

Em seguida, receberam igual pontuação quatro fatores. $\mathrm{O}$ controle e monitoramento efetivos do desenvolvimento das parcerias foi considerado relevante dada a necessidade de aportar subsídios aos gestores para a tomada de ações preventivas e corretivas de forma oportuna nas diferentes etapas da parceria.

Outro fator apontado foi equipe suficiente e qualificada, visto que a necessidade de resposta ágil aos desafios tecnológicos do ambiente farmacêutico. Segundo alguns entrevistados, há um quantitativo insuficiente de profissionais em setores essenciais, como o de análise, ocasionando acúmulo de atividades, assim como há falta de experiência para lidar com os processos das novas tecnologias instaladas.

Ainda foi considerada relevante a gestão de riscos, pela necessidade de se prever possíveis problemas e mitigar a formalização de contratos desgastantes. Por fim, a importância do alinhamento da proposta com o orçamento adequado, para que não faltem recursos para as aquisições e contratações necessárias. 
Além disso, foram citados espontaneamente pelos atores internos outros fatores importantes para o sucesso de uma PDP: compatibilidade da tecnologia a ser transferida com as plataformas produtivas existentes; alinhamento das expectativas entre os entes envolvidos, Ministério da Saúde, parceiro público e privado; aproveitamento da capacidade instalada (área e equipe); eficiente comunicação, tanto interna como externa, capaz de conseguir transmitir a importância das PDPs, seus benefícios e vantagens para a população interessada; compromisso com o cumprimento de prazos; responsabilização; interação entre as áreas internas; estudo de viabilidade técnica e econômica; gestão de mudanças; capacidade decisória da alta direção frente a mudanças; escolha de parcerias com grande volume de produção que gerem ganho de economia de escala e uma boa governança.

Já os atores externos acrescentaram os seguintes fatores: a segurança jurídica para a continuidade das PDPs, sendo que o representante do Ministério da Saúde ainda indicou a capacidade de tomada de decisão dos gestores das unidades públicas frente a mudanças no contexto.

Tendo como referência, especificamente, as PDPs do laboratório estudado, os entrevistados (atores internos) identificaram os fatores, internos e externos ao laboratório, que em suas concepções, influenciaram as trajetórias dessas parcerias (Tabela 3).

Considerando-se os fatores internos, chama a atenção o planejamento insuficiente, com $29 \%$ das indicações recebidas. A falta de integração entre o planejamento estratégico e a gestão de portfólio trouxe dificuldades para a internalização das tecnologias. Segundo os entrevistados, essas PDPs foram assumidas sem ter havido um estudo preliminar com análise de mercado para o cálculo dos custos e dos riscos envolvidos, acarretando atrasos por conta de reprogramações, falta de orçamento, falta de pessoal e necessidade de obras.

A morosidade nas aquisições e obras por conta da burocracia da máquina pública correspondeu a $23 \%$ das indicações. A rigidez na aplicação das regras a toda a máquina pública, desconsiderando as especificidades dos setores, constitui um dificultador ao atendimento de prazos, ainda mais considerando-se a ampla gama de legislações próprias da área de licitação, com destaque para a Lei no 8.666/1993. Outro exemplo reside nas exigências colocadas para a realização de obras públicas, com requisitos socioambientais para a obtenção de licenças, alvarás, autorizações e registros, que trazem uma grande lentidão aos processos.

Mais um fator interno indicado como relevante foi o limitado monitoramento dos prazos e controle das etapas (15\% de indicações). Essa atividade, que é claramente ligada ao planejamento, é de fundamental importância para o acompanhamento do desenvolvimento dos projetos. Segundo alguns entrevistados, esse fator, aliado à falta de cobrança institucional, ocorre, em grande parte, pela falta de clareza quanto às responsabilidades de cada área e pela ausência de ferramentas gerenciais adequadas.

A baixa capacitação dos profissionais envolvidos teve também $15 \%$ das indicações. A insuficiência de conhecimento tácito e de experiência para esse tipo de projeto, principalmente no início do programa, trouxe dificuldades para lidar com os desafios organizacionais, regulatórios e tecnológicos. Por conta disso, alguns entrevistados citaram a necessidade de treinamento e capacitação para os profissionais envolvidos com as PDPs, principalmente para os responsáveis pelo gerenciamento e transferência da tecnologia.

Quanto aos fatores externos houve um destaque para as questões políticas, com $41 \%$ das indicações recebidas. Segundo os entrevistados, as mudanças ocorridas na política do Governo Federal e na legislação que rege as PDPs, foram dificultadores para a formalização e andamento dos acordos. Conforme Varrichio 17 (p. 196), "essa alteração da legislação durante o período de execução da política das PDPs, encarada na perspectiva de uma política de inovação pelo lado da demanda, mostra-se negativa porque demonstra instabilidade e pode alterar as expectativas dos agentes envolvidos". Questões como: mudança de atores nos altos cargos do Ministério da Saúde, descontinuidade de programas, alterações nas demandas e aquisição de medicamentos objeto dos acordos de PDPs no mercado privado, trazem dificuldades para a manutenção dos acordos.

O orçamento insuficiente recebeu 19\% de menções. O histórico subfinanciamento para ações voltadas ao SUS, aliado ao corte de recursos que a área da saúde tem sofrido, traz uma restrição orçamentária que tende a inviabilizar os avanços tecnológicos, trazidos pela transferência de tecnologia. O investimento necessário à incorporação tecnológica é muitas vezes incompatível ao que o Ministério da Saúde está disposto a pagar e, por conta disto, muitas vezes, ocorre uma pressão para a redução do preço do medicamento previamente acordado no Projeto Executivo, o que reduz ainda mais a 
margem que financiaria a transferência da tecnologia. Além disso, durante a execução dos projetos ocorrem percalços tais como mudanças nos projetos trazidas pelos parceiros privados ou a oscilação do dólar, que causam impacto no planejamento orçamentário e fogem da governabilidade do laboratório público. Como consequência, o orçamento insuficiente inviabiliza ou dificulta a implantação das parcerias.

A dificuldade de relacionamento com os parceiros privados também obteve 19\% das menções. Quanto a esse fator parece haver uma dissonância na comunicação entre o laboratório público e o parceiro detentor da tecnologia, com consequente falta de compreensão das responsabilidades de cada um. $\mathrm{O}$ acordo formalizado, em alguns casos, não é suficiente para um entendimento harmônico e tal situação se agrava quando mudanças, embora justificáveis, são implantadas e comunicadas de forma tardia pelos parceiros privados. Esse fato dificulta a operacionalização dos processos e acarreta retrabalho e custos inesperados. Além disso, alguns entrevistados citaram um baixo comprometimento de alguns parceiros para o cumprimento dos prazos e a prestação de um serviço eficiente.

De forma complementar e específica, questionou-se aos atores externos sobre o principal desafio que as PDPs enfrentam por conta do cenário atual. O laboratório privado apontou que a falta de uma base legal forte e duradoura e de uma previsibilidade financeira dos projetos, tendo em vista a insegurança jurídica e econômica que trazem, ocasionam dificuldades para o estabelecimento de novas parcerias. Já o representante do Ministério da Saúde destacou dois desafios. O primeiro referese à capacitação tecnológica (aquisição de equipamentos e treinamento dos recursos humanos) dos produtores públicos, pois, sem isto, os LFOs podem ficar obsoletos e incapacitados de atuarem como instituições de ciência e tecnologia. O outro desafio apontado foi a manutenção pelo LFO do preço a médio e longo prazos. Dada a concorrência, o preço é uma questão extremamente relevante a ser observada para a sustentabilidade da PDP, que deve ser pactuado baseando-se no monitoramento dos preços internacionais, considerando-se principalmente o mercado dos países desenvolvidos, que tenham capacidade de produção e sistema de saúde universais.

\section{Evolução das PDPs no laboratório oficial}

Desde 2009, o laboratório estudado obteve 23 parcerias aprovadas pelo Ministério da Saúde, sendo 22 de medicamentos e 1 de $\mathrm{P} \& \mathrm{D}$, com a participação de três instituições públicas e 20 entidades privadas.

Na Tabela 5, verificou-se que $80 \%$ das parcerias já alcançaram e/ou ultrapassaram a Fase III, o que demonstra que os registros já foram nacionalizados pelo laboratório público e que os medicamentos já são distribuídos para o Ministério da Saúde.

A obtenção do registro é um marco importante das PDPs, visto que é a partir do registro sanitário que o Ministério da Saúde formaliza Termos de Descentralização de Crédito destinados à transferência de recursos ao LFO, permitindo o início das aquisições do medicamento objeto da PDP do parceiro privado e do processo de transferência de tecnologia, para que ao final, o laboratório público esteja apto a produzir o medicamento em escala comercial.

Apesar desse resultado, observa-se um tempo médio elevado para a conclusão da Fase II (3,25 anos). Essa morosidade não é interessante para nenhum dos parceiros envolvidos, já que atrasa o início da Fase III, quando ocorre a transferência de tecnologia propriamente dita, e consequentemente a distribuição do medicamento ao SUS. Além disso, o produto corre o risco de ficar obsoleto, visto a velocidade das inovações do mercado farmacêutico mundial. Cabe ainda destacar que, somente na Fase III, os laboratórios públicos e privados começam a receber os investimentos para a transferência da tecnologia, por meio da venda do medicamento ao Ministério da Saúde, o que reforça a importância de se iniciar esta fase o quanto antes.

A Fase III tem várias atividades que devem ser cumpridas pelo laboratório público, para que ocorra a transferência de tecnologia e dê início à fabricação nacional do medicamento. Dada a sua importância estratégica e para que se possa ter uma ideia sobre a evolução e o desenvolvimento das PDPs, foi realizada uma análise mais detalhada de 3 das 6 PDPs que se encontravam na Fase III, as quais estavam em seu último ano de execução. Comparou-se o que foi planejado nos acordos com o efetivamente realizado, para os cinco anos da PDP (Tabela 4).

Cabe destacar que, na prática, existe uma flexibilidade em relação ao atingimento dos prazos previstos para as atividades no cronograma, desde que não ultrapassem o prazo final do acordo. Para 
o estudo, entretanto, o prazo estipulado para a atividade no cronograma foi considerado sem flexibilidade a fim de se obter uma mensuração mais aproximada do grau de desenvolvimento. O resultado encontrado para cada PDP é apresentado na última coluna da Tabela 4, expresso pelo percentual médio de conclusão das 10 atividades. Na última linha da Tabela 4, visualiza-se o percentual médio de desenvolvimento de cada atividade, independentemente da PDP considerada.

Identificou-se que o percentual médio de conclusão das atividades das PDPs estudadas estava em média de $45 \%$, sendo a parceria do produto 7 , a mais adiantada, com média de 47\%, seguida pelas PDPs dos produtos 4 , com $44 \%$, e 8 , com $43 \%$.

As duas primeiras atividades "primeiro fornecimento do medicamento objeto da PDP" e "registro sanitário do medicamento pela Instituição Pública” pontuaram integralmente, tendo em vista que a primeira constitui o marco de início da Fase III e a segunda por ter sido finalizada dentro do prazo previsto.

Nas atividades relacionadas à transferência de método, necessárias à validação analítica (3a e 4a atividades do ano 1), nota-se que um gargalo começa a se apresentar. Verificou-se maior criticidade na transferência de metodologia do insumo farmacêutico ativo (IFA), visto que não houve conclusão dentro do prazo para nenhuma PDP. Nas entrevistas, foram identificadas algumas possíveis causas para essa situação: número excessivo de projetos a serem analisados, falta de estrutura física (equipamentos) e de pessoal técnico disponível; morosidade para as aquisições dos padrões analíticos e alterações na metodologia analítica pelo detentor da tecnologia.

Quanto à internalização do IFA, etapa obrigatória para a formalização das PDPs de produtos de base sintética, foi verificado junto à coordenação das PDPs que, das 3 PDPs analisadas, apenas um dos parceiros privados já internalizou o IFA do produto (PDP 4), enquanto as outras farmoquímicas parceiras ainda fornecem os IFAs importados.

\section{Conclusão}

O estudo apresentou um diagnóstico da evolução das PDPs de um laboratório oficial público, explicitando os fatores críticos que influenciaram seu desenvolvimento. Além disso, trouxe informações relevantes sobre o contexto das PDPs, vinculados ao ambiente organizacional público, privado e governamental.

Pôde-se depreender que o sucesso das PDPs depende não somente da competência endógena dos laboratórios parceiros, mas também do apoio político por parte do Ministério da Saúde, para que haja segurança jurídica aos acordos e garantia da continuidade dos projetos.

Verificou-se também a necessidade de utilização, pelos laboratórios oficiais, de modelos de gestão mais flexíveis e modernos, com o intuito de reduzir os impactos causados pelas regras de aquisição utilizadas no setor público e de alcançarem uma maior agilidade de resposta às constantes mudanças ocorridas nos ambientes interno e externo. Igualmente, entendeu-se que a gestão realizada pelo Ministério da Saúde pode ser aprimorada, para que ocorra um controle mais eficiente em relação aos prazos e objetivos propostos para as PDPs.

Em relação à identificação dos FCSs que envolvem as PDPs, notou-se uma grande conformidade com os fatores já identificados em outros estudos sobre projetos e PPP, porém, foi possível identificar de forma adicional fatores peculiares a estes projetos, destacando-se: a compatibilidade da tecnologia a ser transferida ao portfólio existente; o alinhamento das expectativas entre os entes envolvidos (Ministério da Saúde, parceiro público e privado); o aproveitamento da capacidade instalada (área e equipe) e a segurança jurídica para a continuidade das PDPs.

A análise da evolução das parcerias do laboratório estudado permitiu verificar que, mesmo ainda não tendo ocorrido a finalização das mesmas, por conta dos atrasos, houve um ganho de vantagens competitivas ao laboratório, com a conquista de novas áreas fabris, aquisição de equipamentos mais modernos e sofisticados, e incorporação de novas tecnologias, possibilitando assim uma diferenciação em seu portfólio e sua sustentabilidade econômica.

Quanto aos benefícios trazidos ao SUS, os atrasos significativos nos cronogramas dos acordos trazem uma dificuldade para esta mensuração, visto que etapas essenciais ainda não foram executadas, englobando, em especial, a falta de internalização dos IFAs e da produção pública dos medicamentos, 
necessárias para a redução da dependência produtiva e tecnológica do país e do déficit da balança comercial em saúde.

Os resultados do estudo ainda demonstraram a existência de desafios organizacionais e governamentais a serem superados para a conclusão das PDPs. Em relação à gestão interna, os maiores desafios identificados têm relação ao planejamento das parcerias, à burocracia administrativa própria da máquina pública e ao monitoramento das etapas. No âmbito governamental, destacaram-se a interferência política e o subfinanciamento.

Por fim, os resultados encontrados indicam a possibilidade de um aprimoramento nos seguintes aspectos.

Inicialmente, destaca-se o processo de planejamento, englobando o gerenciamento dos riscos operacionais, com o intuito de atenuar impactos que falhas processuais ou acordos mal planejados possam causar à imagem e à sustentabilidade financeira do LFO. Esse gerenciamento pode incluir, entre outras ações, a identificação dos riscos, o planejamento de ações de respostas e o seu controle e monitoramento. Ainda no campo do planejamento, o incremento ao estudo de viabilidade técnica e econômica para se averiguar a viabilidade da parceria e os investimentos necessários ao projeto. Esse planejamento é necessário para garantir que o cronograma seja cumprido e haja infraestrutura e orçamento necessários à implantação das PDPs.

Outro aspecto reside no aperfeiçoamento do gerenciamento e monitoramento dos projetos. Verifica-se a necessidade de utilização de softwares ou ferramentas gerenciais adequadas, que permitam um melhor rastreamento de informações, monitoramento dos prazos e emissão de relatórios. Assim possibilitando uma visão holística e transparente dos projetos, e trazendo melhorias na comunicação da equipe de projetos com as áreas envolvidas, como na organização e controle.

Em relação à gestão operacional das PDPs, seria importante que o LFO com mais de uma PDP em andamento constitua uma equipe dedicada e específica para estes projetos. O intuito é otimizar os trabalhos, evitar gargalos e setores sobrecarregados, por conta da confluência com os demais projetos da Unidade e até mesmo entre os próprios projetos de PDPs. Outra estratégia possível, caso o laboratório já tenha uma quantidade suficiente de pessoal, seria a separação de funções e divisão de equipes, para que os profissionais possam se dedicar de maneira específica, sem haver a necessidade de horas extras e trabalhos acumulados.

Por fim, parece ser estratégico uma avaliação contínua da pertinência da continuidade das parcerias em andamento, pelos laboratórios parceiros, principalmente quanto as que ainda não tiveram o registro obtido pelo laboratório público, que estejam com grande atraso ou que seja constatada a impossibilidade de internalização do IFA, levando-se em consideração o desabastecimento do medicamento no SUS e o custo envolvido.

Ressalta-se que o estudo não teve o objetivo de avaliar a política das PDPs, a qual é necessária, porém requer uma análise mais ampla. Além disso, inerente às pesquisas qualitativas, não teve a pretensão de apresentar um resultado conclusivo e passível de generalização, já que analisou o contexto de apenas um LFO.

Contudo, considera-se que foi possível compilar e demonstrar de forma clara informações que poderão ser trabalhadas pelos gestores do laboratório estudado, contribuindo assim para o planejamento estratégico e gerencial destas parcerias.

Além disso, os resultados identificados podem servir de referência para outros laboratórios públicos que tenham acordos de PDPs em andamento ou que pretendam apresentar propostas. Podem também despertar a realização de novos estudos sobre parcerias voltadas para a inovação e soberania nacional em saúde ou sobre a pesquisa de novos fatores críticos, baseados em uma pesquisa mais ampla. 


\section{Colaboradores}

D. R. A. Fernandes contribuiu com a concepção e projeto, análise e interpretação dos dados, redação do artigo, revisão crítica relevante do conteúdo intelectual e aprovação final da versão a ser publicada. S. M. L. Lima e R. P. Chagnon contribuíram com a redação do artigo e revisão crítica relevante do conteúdo intelectual.

\section{Informações adicionais}

ORCID: Daniela Rangel Affonso Fernandes (00000002-0969-2707); Sheyla Maria Lemos Lima (0000-0003-1450-0498); Roberto Pierre Chagnon (0000-0001-8421-7693).

\section{Agradecimentos}

Gostaríamos de agradecer profundamente aos pareceristas pelo tempo dispensado à leitura do estudo e pelas contribuições e críticas construtivas para o aprimoramento do manuscrito.

\section{Referências}

1. Gadelha CAG. Ciência, tecnologia e inovação para um projeto de desenvolvimento e soberania nacional: a perspectiva das mudanças estruturais. https://congressointerno.fiocruz. $\mathrm{br} /$ sites/congressointerno.fiocruz.br/files/do cumentos/Semin\%C3\%A1rio\%203\%20-\%20 Apresenta\%C3\%A7\%C3\%A3o\%20Carlos\%20 Gadelha\%20-\%2018.10.2017_0.pdf (acessado em 09/Jan/2019).

2. Ministério da Saúde. Fluxograma - parcerias para o desenvolvimento produtivo. Anexo 1. http://portalarquivos2.saude.gov.br/images/ pdf/2014/agosto/13/Anexo-I---Fluxograma -PDP.pdf (acessado em 20/Out/2017).

3. Pinheiro ES. Laboratórios farmacêuticos governamentais e o Sistema Único de Saúde. In: Bonfim JR, Mercucci VL, organizadores. A construção da política nacional de medicamentos. São Paulo: Editora Hucitec/Rio de Janeiro: Abrasco; 1997. p. 81-6.

4. Gadelha CAG. O complexo industrial da saúde e a necessidade de um enfoque dinâmico na economia da saúde. Ciênc Saúde Colet 2003; 8:521-35.

5. Ministério da Saúde. Grupo Executivo do Complexo Industrial da Saúde - GECIS. http:// www.saude.gov.br/ciencia-e-tecnologia-ecomplexo-industrial/complexo-industrial/ grupo-executivo-do-complexo-industrial-dasaude-gecis (acessado em 15/Jun/2019).

6. Ministério da Saúde. Parcerias para o Desenvolvimento Produtivo (PDP). http://portalms. saude.gov.br/ciencia-e-tecnologia-e-complexo -industrial/complexo-industrial/parceria-para -o-desenvolvimento-produtivo-pdp (acessado em 10/Jun/2018).

7. Ministério da Saúde. Portaria GM/MS no 837, de 18 de abril de 2012. Define as diretrizes e os critérios para o estabelecimento das Parcerias para o Desenvolvimento Produtivo (PDP). Diário Oficial da União 2012; 27 abr.

8. Ministério da Saúde. Portaria no 2.531, de 12 de novembro de 2014. Redefine as diretrizes e os critérios para a definição da lista de produtos estratégicos para o Sistema Único de Saúde (SUS) e o estabelecimento das Parcerias para o Desenvolvimento Produtivo (PDP) e disciplina os respectivos processos de submissão, instrução, decisão, transferência e absorção de tecnologia, aquisição de produtos estratégicos para o SUS no âmbito das PDP e o respectivo monitoramento e avaliação. Diário Oficial da União 2014; 13 nov.

9. Gadelha CAG, Costa L. Saúde e desenvolvimento no Brasil: avanços e desafios. Rev Saúde Pública 2012; 46 Suppl:13-20. 
10. Vargas MA, Almeida ACS, Guimarães ALC. Parcerias para desenvolvimento produtivo (PDPS-MS): contexto atual, impactos no sistema de saúde e perspectivas para a política industrial e tecnológica na área de saúde. Rio de Janeiro: Fundação Oswaldo Cruz; 2017.

11. Sundfeld CA. Parcerias público-privadas. São Paulo: Malheiros; 2005.

12. Rezende KS. As parcerias para o desenvolvimento produtivo e estímulo à inovação em instituições farmacêuticas públicas e privadas [Dissertação de Mestrado]. Rio de Janeiro: Escola Nacional de Saúde Pública Sergio Arouca, Fundação Oswaldo Cruz; 2013.

13. Shenhar AJ, Dvir D. Reinventing project management: the diamond approach to successful growth and innovation. Boston: Harvard Business School Press; 2007.
14. Menezes DC. Fatores críticos para a estruturação de parcerias público-privadas no Governo Federal [Dissertação de Mestrado]. Brasília: Universidade de Brasília; 2014.

15. Morioka S, Carvalho MM. Análise de fatores críticos de sucesso de projetos: um estudo de caso no setor varejista. Production 2014; 24:132-43.

16. Borges JG, Carvalho MM. Critérios de sucesso em projetos: um estudo exploratório considerando a interferência das variáveis tipologia de projetos e stakeholders. Production 2015; 25:232-53.

17. Varrichio PC. As parcerias para o desenvolvimento produtivo da saúde. In: Rauen AT, organizador. Políticas de inovação pelo lado da demanda no Brasil. Brasília: Instituto de Pesquisa Econômica Aplicada; 2017. p. 179-234. 


\section{Abstract}

Product Development Partnerships (PDP) are one of the measures used by the Brazilian government to incentivize innovation policy, to expand the population's access to strategic medicines, and to reduce the country's technological dependence by strengthening the national pharmaceutical manufacturing base. The study aimed to identify the Critical Success Factors (FCS in Portuguese) for the implementation of these partnerships, using as the reference one of the largest Brazilian government pharmaceutical laboratories. FCS are seen as key areas in which the results must be satisfactory in order to ensure successful performance in the organization or project. The methodological strategies included literature review, analysis of internal documents, and semi-structured interviews with key actors. We analyzed the partnerships approved for this public laboratory from 2009 to May 2018. The study enabled a critical view of the phases in a PDP and identification of specific critical factors for this type of project. The findings reveal persistent organizational challenges for increasing the executability of partnerships, which can serve as a reference for other government laboratories that have PDP agreements under way or that intend to submit proposals for them.

Health Policy; Drug Industry; Public-Private Sector Partnerships; Health Sciences, Technology, and Innovation Management

\section{Resumen}

Las Alianzas para el Desarrollo Productivo (PDP por sus siglas en portugués) es una de las medidas usadas por el estado brasileño para incentivar la política de innovación, ampliar el acceso de la población a medicamentos estratégicos y reducir la dependencia tecnológica del país, a través del fortalecimiento de la base productiva nacional de medicamentos. El trabajo buscó identificar los Factores Críticos de Éxito (FCS por sus siglas en portugués) para la implementación de esas colaboraciones, teniendo como referencia las PDPs de uno de los mayores laboratorios farmacéuticos oficiales del pais. Los FCS se entienden como las áreas-clave en las que los resultados deben ser satisfactorios para asegurar un desempeño de éxito para la organización o proyecto. Como estrategias metodológicas, además de la revisión bibliográfica $y$ análisis de documentos internos, se realizaron entrevistas semiestructuradas con actores-clave. Se consideraron las colaboraciones aprobadas para el laboratorio durante el período de 2009 a mayo de 2018. El estudio permitió una visión crítica sobre las fases del proceso de una PDP y la identificación de factores críticos específicos para ese tipo de proyecto. Los resultados encontrados demuestran que existen desafíos organizativos que deben superarse para que aumente la posibilidad de ejecución de colaboraciones y puedan servir de referencia para otros laboratorios oficiales que tengan acuerdos de PDPs en transcurso o que pretendan presentar propuestas.

Política de Salud; Industria Farmacéutica; Asociación entre el Sector Público-Privado; Gestión de Ciencia, Tecnología e Innovación en Salud
Recebido em 25/Mar/2019

Versão final reapresentada em 27/Jun/2019 Aprovado em 25/Jul/2019 